ARTIGOS

\title{
UNILA: A UNIVERSIDADE COMO VETOR DA INTEGRAÇÃO REGIONAL*
}

\author{
Ivor Prolo ${ }^{1}$ (1) \\ Manolita Correia Limaª \\ Gonçalo Canto Moniz ${ }^{3}$ •
}

\begin{abstract}
RESUMO: Este artigo teve como propósito compreender o significado do projeto de criaçáo da Universidade Federal da Integração Latino-Americana (UNILA) como uma universidade que pretende promover a integraçáo regional para a América Latina e o Caribe pelas vias do conhecimento e da cultura. A pesquisa assumiu caráter de ensaio teórico e combinou recursos das pesquisas bibliográfica e documental. $\mathrm{O}$ artigo explorou conceitos e fez um comparativo sobre a integração regional da América Latina e da União Europeia. Em seguida, identificou o direcionamento das relaçóes internacionais do governo brasileiro entre 2003-2010 e , finalmente, caracterizou os elementos centrais que compóem o projeto original da UNILA, discutindo suas potencialidades, tensóes e limitaçóes para a sua existência.
\end{abstract}

Palavras-chave: Integração regional. Universidade brasileira. Internacionalização da educação superior. Universidade Federal da Integração Latino-Americana.

\section{UNILA: THE UNIVERSITY AS VECTOR OF REGIONAL INTEGRATION}

ABSTRACT: This paper has the purpose to understand the significance of the creation project of the Federal University of Latin American Integration (UNILA) as a university that aims to foment regional

\footnotetext{
*Este artigo é derivado do projeto de pesquisa intitulado Mobilidade acadêmica internacional e integração regional: um estudo na Universidade Federal da Integração Latino-Americana, financiado pelo Conselho Nacional de Desenvolvimento Científico e Tecnológico (CNPq) entre 2015 e 2017 pela chamada CNPq/ Ministério da Ciência, Tecnologia e Inovação (MCTI)/Universal no 014/2014. Também constitui parte de tese de doutorado financiada por meio da bolsa — código 001 —, pela Coordenaçáo de Aperfeiçoamento de Pessoal de Nível Superior (Capes).

${ }^{1}$ Universidade do Estado de Mato Grosso - Nova Xavantina (MT), Brasil. E-mail: ivorprolo@unemat.br ${ }^{2}$ Escola Superior de Propaganda e Marketing - São Paulo (SP), Brasil. E-mail: mclima@espm.br ${ }^{3}$ Universidade de Coimbra - Coimbra, Portugal. E-mail: gcmoniz@gmail.com DOI: 10.1590/ES0101-73302019189894
} 
integration for Latin America and the Caribbean through knowledge and culture. The research assumes the character of theoretical essay and combines resources of bibliographical and documentary research. The article explores concepts and makes a comparison of regional integration between Latin America and the European Union (EU). Next, it identifies the direction of the international relations of the Brazilian government between 2003-2010 to finally characterize the central elements that compose the original UNILA project to discuss its potentialities, tensions and limitations for its existence.

Keywords: Regional integration. Brazilian university. Internationalization of higher education. Federal University of Latin American Integration.

\section{UNIVERSIDAD FEDERAL DE LA INTEGRACIÓN LATINOAMERICANA (UNILA): LA UNIVERSIDAD COMO VECTOR DE LA INTEGRACIÓN REGIONAL}

RESUMEN: Este artículo tiene el propósito de comprender el significado del proyecto de creación de la Universidad Federal de la Integración Latinoamericana (UNILA) como universidad que pretende promover la integración regional para América Latina y el Caribe por las vías del conocimiento y la cultura. La investigación asume carácter de ensayo teórico y combina recursos de las investigaciones bibliográfica y documental. El artículo explora conceptos y hace un comparativo sobre la integración regional de América Latina y de la Unión Europea (UE). En seguida, identifica el direccionamiento de las relaciones internacionales del gobierno brasileño entre 2003-2010 para, finalmente, caracterizar los elementos centrales que componen el proyecto original de la UNILA, para discutir sus potencialidades, tensiones y limitaciones para su existencia.

Palabras clave: Integración regional. Universidad de Brasil. Internacionalización de la educación superior. Universidad Federal de la Integración Latinoamericana.

\section{Introdução}

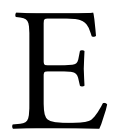

ntre os séculos XIX e XX, as universidades ocidentais diferenciaram-se em consonância com os respectivos propósitos (missão), formas de institucionalização, regulamentação, padrão de financiamento e dedicação ao atendimento de interesses sociais, políticos e econômicos das naçóes, justificando a formação de distintos modelos históricos (RUBIÂO, 2013). Apesar da emergência de novas arquiteturas universitárias, a instituição adotou a produção e a difusão do conhecimento como elementos centrais. Enquanto no século XII a centralidade do conhecimento estava restrita ao âmbito pessoal, no século XX o 
conhecimento passou a ser compreendido como instrumento político e estratégico decisivo para os desenvolvimentos local, regional e internacional, na medida em que, embora limitado à formaçáo acadêmica da elite, era amplamente difundido e incorporado pelos ambientes produtivos (AVEIRO, 2014).

No século XX, a universidade pública latino-americana foi pressionada a produzir conhecimento capaz de gerar soluçóes para problemas socioeconômicos enfrentados por vários países da região, a colaborar para os desenvolvimentos regional e nacional, além de promover a democratização do seu acesso. A concepção de uma universidade mais popular, democrática e socialmente comprometida era uma das reivindicaçóes do Movimento de Córdoba - Argentina, 1918 - (DIAS, 2018), assim como das Assembleias da União de Universidades da América Latina e Caribe (Udual) na década de 1960 (TRINDADE, 2012). Para o movimento, a exemplo do que propóe Mello (2011), a universidade pública deveria servir ao bem coletivo, promover os direitos humanos e contribuir para a promoção da qualidade da educação, da ciência e da cultura.

No início do século XXI, a agenda do Movimento de Córdoba previa aproximação política entre os governos dos países sul-americanos na busca por um diálogo qualificado capaz de cooperar para a integração regional (PECEQUILO; CARMO, 2015). A discussão sobre a essência da universidade, associada ao interesse de promover a integração entre os países da região, inspirou o projeto de criação da Universidade Federal da Integração Latino-Americana (UNILA), em 2010. Apesar de os debates sobre o propósito integracionista universitário terem se intensificado entre os países da regiáo, a UNILA foi criada por iniciativa do governo federal brasileiro, refletindo as políticas externas (compromisso com a integração regional) e sociais (compromisso com a inclusão social) do período compreendido entre 2003-2010 (MENEGHEL; AMARAL, 2016). Assim, o referido projeto embalava o ideal de uma "universidade necessária" (RIBEIRO, 1978), porque "socialmente relevante" (MELLO; ALMEIDA FILHO; RIBEIRO, 2009) e comprometida com a integração regional pelas vias do conhecimento e da cultura (IMEA, 2009a; RICOBOM, 2010).

Coerente com tal propósito, o projeto de criação da UNILA fortalecia uma identidade institucional singular na medida em que previa a existência de uma universidade bilíngue (espanhol e português como línguas maternas oficiais), adotava a abordagem interdisciplinar e destacava a interculturalidade como o valor e o foco da integração regional. Constituía-se como um espaço de convivência intercultural, de produção e de difusão de conhecimento entre estudantes e professores oriundos de diferentes países latino-americanos (IMEA, 2009a; RICOBOM, 2010), numa espécie de mobilidade acadêmica internacional solidária (CASTRO; CABRAL NETO, 2012), em contraponto "ao assistencialismo dominador e ao internacionalismo mercantil” (SPELLER, 2011, p. 9).

Apesar de ainda ter pouco tempo de existência (2010-2019), os ideais que nutriam o projeto da UNILA têm suscitado interesse da academia. Observa-se 
que grande parte dos resultados das pesquisas publicadas aprofunda aspectos relacionados às motivaçóes que justificam a criação da instituição (ROSEVICS, 2015), a integração regional (CORAZZA, 2010; RICOBOM, 2010), a internacionalização da educação superior (ABBA, 2018), a interculturalidade e o multilinguismo (ARAÚJO, 2014; MUNOZ, 2016) e o seu caráter contra-hegemônico (MENEGHEL; AMARAL, 2016), contudo nenhuma delas discute o projeto de criação da UNILA com vistas a aprofundar as tensôes e as incertezas que colocam em dúvida a sua sobrevivência.

Objetivando contribuir para o avanço do debate em curso, pretende-se situar os contextos latino-americano e brasileiro que propiciaram a formulaçáo do arrojado projeto de criação da UNILA, buscando discutir a esperança que embala a concepção dessa universidade e as possibilidades que seus primeiros anos de existência descortinam, sem desconsiderar os desafios nem as incertezas que colocam em risco o futuro de uma instituição que insiste em viver uma microutopia, nostermos propostos por Santos (2013).

Complementarmente, almeja-se contribuir para o debate acerca das transformaçóes vividas pelas universidades na contemporaneidade, enfatizando a realidade latino-americana. Para tanto, discutem-se os significados atribuídos à internacionalização da educação superior latino-americana e à mobilidade acadêmica internacional (MAI), com vistas à explicitação dos vários sentidos impressos ao conceito de integração regional.

O texto aproxima-se de um ensaio teórico (MENEGHETTI, 2011), combina recursos típicos das pesquisas documental, sobretudo bibliográfica. Explora os conceitos e a cronologia da integração regional na América Latina paralelamente com a integração da Uniáo Europeia, bem como identifica o direcionamento internacional brasileiro entre 2003-2010, resgata os elementos centrais que compóem o projeto original da UNILA e problematiza as tensóes e as incertezas que a universidade tem enfrentado no curso do processo de implantação do seu projeto fundador.

\section{Da integração regional europeia às tentativas de integração latino-americana}

Os processos de integração regional são desafiadores para os governos das naçóes por exigir vontade política capaz de alinhar interesses que transitem entre as áreas econômica, social e cultural. Em muitos casos, os países apresentam dificuldades de equalizar as divergências entre os interesses internos e a projeção de políticas externas, revelando, como "amálgama superior, o interesse nacional" (CERVO; BUENO, 2015, p. 526). Para que o conceito de integração ultrapasse o âmbito comercial, enfatiza-se a unificação de uma sociedade a ponto de modificar 
seus sistemas econômico, político e cultural, com o intuito de sustentar as necessidades sociais, imprimindo o sentido de comunidade.

De certa forma, a unificação de uma sociedade tem como objetivo suprimir ou amenizar os antagonismos que a dividem, considerando as lutas e potencialidades que a afetam ou a destroem, alcançando, assim, condiçóes para o crescimento, sem comprometer a própria identidade. Por outro lado, integrar uma sociedade ultrapassa essa definição pelo fato de náo levar em conta apenas a supressão dos antagonismos que a atingem, mas "desenvolver as solidariedades que as unem" (SCHAPOSNIK, 1997, p. 186). Esse conceito de integração, aliado ao sentido de comunidade, exprime o posicionamento teórico dos autores do presente texto.

O campo científico das relações internacionais tem contribuído para aprofundar o conhecimento sobre os processos de integração regional. A União Europeia é a referência de integração que mais revela resultados positivos em termos de unificação dos interesses nacionais em prol dos interesses regionais. Tais êxitos são oriundos de uma política de desenvolvimento regional (PDR) que tem priorizado três eixos: a convergência de interesses dentro dos países e entre eles; a competitividade regional; e a cooperação territorial e econômica europeia. Todos esses eixos são suportados pelo Fundo Europeu de Desenvolvimento Regional (FEDER).

$\mathrm{Na}$ Uniáo Europeia, o conceito de cidadania europeia ganhou centralidade na medida em que fortaleceu a integração dos países daquele continente, promoveu a criação de uma identidade una e, consequentemente, materializou a concepção de uma só comunidade (RODRIGUES, 2011). Um marco nessa construção da cidadania europeia foi a Declaração de Bolonha, publicada em 1999. Trata-se de um acordo voluntariamente celebrado entre 29 países europeus que prevê o Espaço Europeu de Ensino Superior como instância responsável pela promoção de reformas nos sistemas educacionais dos países-membros e pela geração de um sistema universitário unificado capaz de reconhecer os diplomas expedidos e as profissóes regulamentadas, além de influir sobre a competitividade internacional e a promoção da empregabilidade entre os cidadãos europeus dos países que integram o bloco (CASTRO; CABRAL NETO, 2012).

Outro instrumento da integração europeia que se revelou eficaz foi o European Region Action Scheme for the Mobility of University Students (Erasmus), programa de MAI mais difundido na Europa cujo objetivo é colaborar para a construção do Espaço Europeu de Ensino Superior. O referido programa favorece a formação da "cidadania global de educação" (global citizenship education) e da cidadania europeia, antes mencionada, uma vez que ajuda a fortalecer a identidade e a integração europeia por meio das experiências acadêmicas e culturais entre os estudantes (MOROSINI; DALLA CORTE; GUILHERME, 2017). Pode-se afirmar, portanto, que a integração europeia tem explorado dois caminhos paralelos e complementares: um centrado na administração pública, com a construção de um sistema de ensino comum, e outro centrado no estudante, com a promoção da MAI. 
A integração foi o caminho encontrado pelos países europeus para enfrentar os efeitos das graves crises (moral, social, econômica e política) decorrentes dos conflitos que deflagraram a Primeira e a Segunda Guerra Mundial. Considerando os pontos de referência antes descritos, seria possível afirmar que a integração europeia guarda alguma semelhança com o processo de integração latino-americano? Até o momento, pode-se dizer que o processo de integração europeia ganhou mais amplitude de propósitos e reuniu mais avanços que o latino-americano, apesar de eles terem emergido em períodos próximos - décadas de 1950 e 60, respectivamente. Ao promover a integração regional, os países da América Latina sinalizaram claro interesse de incrementar as respectivas participaçôes no comércio internacional. Na década de 1960, por exemplo, criaram a Associação Latino-Americana de Livre Comércio (ALALC). O fracasso da iniciativa abriu espaço, 20 anos depois, para a criação da Associação Latino-Americana de Integração (ALADI), mas, em termos de integração regional, a ALADI tem feito modestas contribuiçóes (SCHAPOSNIK, 1997).

Reforçando o argumento anterior, um aspecto positivo associado à ALADI é o incentivo à formação de Acordos de Complementação Econômica (ACE), que favorecem a criação de associações e organizaçōes sub-regionais na América Latina, tal qual o Mercado Comum do Sul (Mercosul). Criado em 1991, ele tem aproximado, originalmente, quatro países geograficamente próximos: Argentina, Brasil, Paraguai e Uruguai ${ }^{1}$. Sua atuação tem se limitado a questôes comerciais e econômicas, encontrando-se, atualmente, em um estágio de união aduaneira, com dificuldades para avançar na direção de um mercado comum, caracterizado pela livre circulação de bens (mercadorias, serviços e capitais) e de pessoas entre os países-membros (ARAÚJO, 2008).

Constata-se que os países que integram o Mercosul imprimem distintos significados à região, a depender do grau de volatilidade histórica e da orientação político-ideológica dos governantes, fatores que se refletem nas respectivas políticas externas. Contudo, partindo do princípio que, "sem vontade política, não há integraçáo" (ARAÚJO, 2008, p. 135), o diálogo integracionista fortalece-se no âmbito da União de Nações Sul-Americanas (UNASUL), cujos objetivos transitam entre o político, o geopolítico e o econômico, com prioridade para a integração física antes da econômica, por meio do projeto de Integração da Infraestrutura Regional Sul-Americana (IIRSA) (PECEQUILO; CARMO, 2015). Tais projetos são consequência da aproximação de governos progressistas no início da primeira década do século XXI, eleitos na Argentina (Néstor Kirchner, em 2003), Brasil (Luiz Inácio Lula da Silva, em 2003), Uruguai (José Alberto Mujica Cordano, em 2005) e Bolívia (Evo Morales, em 2006) (ROSEVICS, 2015).

Concomitantemente, intensificaram-se as discussões no âmbito do Mercosul Educacional sobre como a educação e a cultura poderiam contribuir para o processo de integração regional. Com base em tais debates, Rosevics (2015) 
distingue duas políticas de integração: a integração da educação e a integração via educação. Enquanto a primeira tem por objetivos promover o intercâmbio estudantil, uniformizar as estruturas educacionais para integrar os sistemas educacionais e facilitar a livre circulação de trabalhadores e prestadores de serviços entre os países-membros; a segunda busca integrar estudantes e professores de diferentes países em um mesmo espaço de convivência educacional e de reconhecimento mútuo, com o intuito de encontrar soluções para os problemas regionais em uma dinâmica integracionista. $\mathrm{O}$ que diferencia essas duas políticas?

A integração da educação baseia-se numa integração estrutural entre os sistemas de educação dos países do Mercosul, e seu papel é secundário e complementar para um projeto central — o econômico. A integração via educação, por sua vez, prioriza a "construção de uma consciência social regional integradora" (ROSEVICS, 2015, p. 32), na qual os projetos políticos e socioculturais ganham destaque. Portanto, como ocorre com a União Europeia, o conceito de cidadania ganha centralidade. Embora o conceito de integração tenha sentidos diferentes nas duas políticas, a integração da educação representa, segundo Rosevics (2015), uma equalização das estruturas educacionais entre os países-membros do Mercosul, podendo criar e multiplicar espaços educacionais capazes de colaborar para promover a integração via educação e cultura.

Pelo exposto, qual alternativa seria coerente com a visão de integração via educação? $\mathrm{O}$ investimento na criação de universidades supranacionais poderia ser um caminho. Ressalta-se que o primeiro registro sobre a ideia de criar uma universidade supranacional na América Latina ocorreu em 1967, em uma Assembleia da UDUAL (TRINDADE, 2012). A proposta foi retomada com o acirramento da discussão sobre integração via educação no Mercosul Educacional, no início do século XXI. Denominado de Universidade do Mercosul, o projeto previa uma instituição de status supranacional, com campi nos diversos países do bloco sul-americano, contudo a ideia não se concretizou em termos de açôes (ROSEVICS, 2015). O insucesso da construção de uma universidade supranacional evidencia a fragilidade das iniciativas de integração regional na América do Sul e na América Latina.

\section{A criação de uma universidade brasileira orientada pela e para a integração latino-americana}

Elementos como estabilidade econômica, recuperação da capacidade de negociação internacional do governo brasileiro e políticas sociais voltadas para o combate às desigualdades sociais, particularmente o combate à fome, credenciaram o Brasil a fomentar e assumir estratégias voltadas para a integração sul-americana com pretensões latino-americanas no início do século XXI (CERVO; BUENO, 2015). Uma dessas estratégias foi a UNILA, assumida por iniciativa unilateral do governo brasileiro (ROSEVICS, 2015) e criada da confluência de 
duas políticas brasileiras: a externa ${ }^{2}$, orientada por um maior protagonismo global; e a de educaçáo superior ${ }^{3}$, direcionada para a expansão do sistema universitário público (MENEGHEL; AMARAL, 2016).

A concepçáo do projeto de criação da UNILA exigiu dois anos de trabalho (2008/2009) e contou com o respaldo de universidades brasileiras e internacionais, institutos de pesquisa governamentais e organismos científicos nacionais e internacionais, além de consulta internacional a especialistas. O livro intitulado UNILA em construção: um projeto universitário para a América Latina (IMEA, 2009b) reúne a essência das discussões coordenadas pelos membros da Comissão de Implantação da UNILA, das quais se originou o projeto político, pedagógico e administrativo da instituiçáo, inspirado na herança do movimento de modernizaçáo universitária liderado pela Universidad Nacional de Córdoba (Argentina, 1918) e nas ideias de Darcy Ribeiro, idealizador do projeto de criação da Universidade de Brasília (Brasil, 1962).

O Movimento de Córdoba representa o princípio de uma corrente ideológica de universidade tipicamente latino-americana. Simboliza a ruptura com uma universidade apegada à herança colonial e à emergência de uma universidade autônoma, pública, gratuita e democrática, que inclui a participação dos estudantes nas decisóes internas. Apresenta como principal legado o engajamento interessado na transformação da sociedade, na justiça social (RUBIÂO, 2013), o que, possivelmente, explica a centralidade do conceito de extensão universitária para a universidade latino-americana.

Na mesma trilha, Darcy Ribeiro (1978) reforça a importância de a universidade latino-americana assumir protagonismo intelectual público ao construir as bases de uma consciência nacional democrática por meio de uma ciência comprometida. Repudia a existência do conhecimento científico neutro por considerar a universidade, por essência, uma instituição social na qual sobrevivem ideologias e interesses e, por assim o ser, politizada. Defende que a universidade latino-americana deveria colaborar para o desenvolvimento autônomo das naçóes das regióes, com base em uma consciência crítica, não submetida à reprodução de interesses nem à lógica dominante de poder, as quais não rompem com as condiçôes de atraso nem com as de subdesenvolvimento.

Para Ribeiro (1978), a principal função da universidade reside na influência que pode exercer para modificar o seu entorno regional, nacional e/ou internacional. Suas aspiraçôes reforçam o ideal de uma universidade pública autônoma, democrática, inclusiva e propositiva, com condiçóes de mapear caminhos na construção de uma sociedade focada no conhecimento autóctone e preocupada com o desenvolvimento sustentável, nunca desconsiderando o conhecimento universal. Nesse contexto, a universidade é um lugar estratégico para promover a integração via cultura e conhecimento, uma vez que a "cultura é vista como um 
fator determinante no comportamento do Estado e dos processos de integraçáo regional" (ARAÚJO, 2014, p. 8).

Inspirada por tal matriz de pensamento, a UNILA tem como princípio básico que orienta a elaboração de seu projeto fundador o compromisso de "promover a integração pelo conhecimento e pela cultura, para subsidiar a aspiração histórica de uma América Latina solidária e integrada em seus objetivos comuns" (IMEA, 2009a, p. 8), tendo por base três pilares:

1. interação em termos nacionais e transnacionais de forma solidária e com respeito mútuo;

2. compromisso com o desenvolvimento econômico sustentável, tornando-o indissociável da justiça social e do equilíbrio do meio ambiente;

3. compartilhamento recíproco de recursos e conhecimentos científicos e tecnológicos com professores e estudantes da América Latina (IMEA, 2009b, p. 16).

Coerentemente com o princípio exposto, o projeto de criação da UNILA enfatiza o diálogo transnacional entre os países da América Latina por meio da presença de estudantes e professores latino-americanos e caribenhos, da valorização da diversidade cultural pautada pela solidariedade e do desenvolvimento sustentável das sociedades mediante a criação de uma identidade latino-americana viabilizada pelo compartilhamento recíproco da cultura e do conhecimento orientado por um ambicioso ideal: contribuir para a promoção da integração regional solidária na América Latina e Caribe. Trata-se de um projeto particularmente audacioso, uma vez que assume os desafios intrínsecos aos processos de integração regional que ousam ultrapassar os limites da integração comercial.

Dessa forma, a UNILA chama para si a responsabilidade de promover a integração regional a começar pelo ambiente universitário (BRASIL, 2013). Logo, não surpreende que assuma explícito compromisso "com o destino das sociedades latino-americanas" (IMEA, 2009b, p. 9), já que sua inspiração advém do Movimento de Córdoba e da concepção de universidade de Darcy Ribeiro. Percebe-se que a integração regional, expressa na missão da UNILA, dialoga com o que Ribeiro (1978) atribui à universidade, ou seja, a integração social das populaçôes latino-americanas por meio da valorização de suas múltiplas e variadas culturas nacionais, capazes de, unidas, formarem uma civilização latino-americana.

Chama-se a atenção para o fato de o projeto de fundação da UNILA explicitar a pretensão de fortalecer o Mercosul, citado em sua missão, e ao mesmo tempo náo permanecer limitado ao espaço sul-americano. Rosevics (2015) 
esclarece que essa amplitude de atuação se deve a ajustes no direcionamento da política internacional brasileira no curso dos dois mandatos do governo de Luiz Inácio (2003-2010). Enquanto o primeiro mandato (2003-2006) teve seu foco voltado para a América do Sul, o segundo (2007-2010) expandiu o raio de interesse para a América Latina, no período em que o projeto de criaçáo da instituição foi gestado. Torna-se possível afirmar que a UNILA constitui parte da política externa desse governo, em que o Brasil assumiu a liderança pelo processo de integração regional, em primeiro lugar no âmbito da América do Sul e, posteriormente, da América Latina.

Os responsáveis pela criação da UNILA revelavam pretensóes de a instituição colaborar para a construção de uma identidade latino-americana, semelhantemente aos objetivos do Processo de Bolonha em relação ao Espaço Europeu de Ensino Superior, apesar de reconhecerem a presença de diferenças, tanto no âmbito da fundamentação quanto no das práticas implementadas. O primeiro teve financiamento de origem pública e acesso gratuito à educação superior, além de ter mobilizado incentivos financeiros para a população estudantil oriunda de estratos sociais economicamente vulneráveis, o que revela comprometimento com uma integração autêntica e solidária, orientada pela promoção da igualdade social dos povos da América Latina. O Processo de Bolonha, por sua vez, esteve voltado para uma integraçáo que priorizava a competitividade, na medida em que nutria o objetivo de cooperar para que os países da Uniáo Europeia se tornassem mais atrativos na recepção de acadêmicos europeus e internacionais, atraindo recursos capazes de contribuir para a manutenção e o financiamento de suas universidades, além de inibir a fuga de cérebros e divisas.

Embora a UNILA tenha tido foco internacional em razão do fluxo de estudantes forâneos que acolhia - em 2017, de um montante de 3.971 estudantes, $31 \%$ eram internacionais (BRASIL, 2018) —, ainda náo pode ser reconhecida como uma universidade internacionalizada. Ela comprometia-se a promover a mobilidade acadêmica inter-regional, o que que remete, mesmo timidamente, à formação de uma consciência identitária regional, comparável ao conceito de cidadania europeia (MOROSINI; DALLA CORTE; GUILHERME, 2017). Atualmente, a UNILA integra quatro institutos (Instituto Latino-Americano de Arte, Cultura e História - ILAACH; Instituto Latino-Americano de Ciências da Vida e da Natureza - ILACVN; Instituto Latino-Americano de Economia, Sociedade e Política - ILAESP - e Instituto Latino-Americano de Tecnologia, Infraestrutura e Território - ILATIT), que agrupam 29 cursos de graduação, oito cursos de mestrados e um de doutorado. A instituição prioriza o ingresso de estudantes internacionais por mérito acadêmico e perfil de vulnerabilidade socioeconômico, critérios que justificam os fatos de, em 2015, ter reunido 37\% de estudantes autodeclarados indígenas, pardos e pretos e também de, nos primeiros anos de sua existência (2010 a 2013), quase a totalidade dos estudantes terem recebido alguma forma de assistência estudantil (BRASIL, 2018). 
Portanto, a essência do projeto de criação de uma universidade brasileira para a América Latina promove a disseminação de uma consciência integradora nos seguintes aspectos:

- o direcionamento de um olhar voltado para o continente e para o povo latino-americano (RICOBOM, 2010);

- o conceito de integração regional ultrapassa a dimensão comercial/ econômica, priorizando fundamentos que transitam entre os aspectos sociais, políticos e, principalmente, culturais (CORAZZA, 2010);

- a promoção de um espaço universitário intercultural capaz de criar e "gestar um pensamento estratégico que beneficie o continente" (ARAÚJO, 2014, p. 4);

- um centro irradiador de potencialidades para a América Latina em geral e para a América do Sul particularmente (ROSEVICS, 2015).

Essa consciência integradora perpassa pela MAI solidária entre os acadêmicos, na medida em que o cotidiano é permeado de experiências culturais que favorecem o autoconhecimento e o conhecimento do outro, multiplicando as oportunidades de se ultrapassar os limites da tolerância, na direção da formação de sólidos laços de amizade entre os unileiros (CHIBIAQUI; LIMA; NIHEI, 2019).

\section{Tensões e incertezas}

Apesar de o propósito justificador da criação da UNILA inspirar não apenas seus idealizadores e de a universidade reunir conquistas em seu reduzido tempo de existência (PROLO, 2019), o processo de implantação do projeto fundador da instituição tem sido marcado por tensões e incertezas: por um lado, a existência de um projeto arrojado e, por outro, os desafios que emergem na implantação de um projeto arrojado, particularmente ambicioso, em contextos sociais, políticos e econômicos crescentemente adversos.

Os obstáculos vividos no processo de implantação do projeto fundador da UNILA podem ser discutidos em três níveis, macro, meso e micro. No nível macro há indefiniçóes quanto ao processo de implantação do projeto original. As mudanças no âmbito do governo federal (Lula-Dilma-TemerBolsonaro) implicam alteraçōes na matriz político-ideológica, as quais podem representar desinteresse político pela integração regional, pelo financiamento de uma universidade pública cuja missão é a integração regional solidária e pela manutenção de uma política de inclusão de estudantes em vulnerabilidade socioeconômica e de acadêmicos internacionais (CORAZZA, 2010; LIMA et al., 2016). Entretanto, levando em conta o avanço de um processo 
de globalização econômica, a missão integracionista da UNILA pode contribuir para o fortalecimento de uma região marcada por assimetrias territoriais e econômicas importantes. Assim sendo, cabe questionar: com a ascensão de lideranças conservadoras na regiáo, em que medida é possível afirmar que os países da América Latina se revelam interessados em fortalecer as iniciativas voltadas para a integração regional? Em que medida tais projetos de governo estão alinhados com os princípios fundadores que sustentam o projeto de criação da UNILA? Até que ponto a UNILA poderia ser favorecida com contrapartidas dos países da América Latina, seja no âmbito cultural, seja no acadêmico, político ou econômico? Até que ponto o governo federal, em geral, e o Itamarati, particularmente, preservam o alinhamento de interesses estratégicos internacionais com os propósitos da universidade?

No âmbito meso há incertezas sobre a contribuição da UNILA para a cidade de Foz do Iguaçu. Historicamente existe uma relação virtuosa entre universidade e cidade, tendo em vista que a universidade pública no Brasil representa um polo irradiador de progresso regional em virtude da geraçáo de conhecimentos técnico e científico, da atração e formação de talentos de nível superior, da demanda por infraestrutura e serviços e da oferta de serviços por meio dos programas de extensão coordenados pela universidade, por exemplo. No entanto, até o momento, a face mais visível da instituição é a chegada de uma populaçáo estudantil muito diferente dos turistas que a cidade está habituada a acolher, uma vez que eles são muito jovens e em número crescente; assumem o status de estudante em tempo integral e a sobrevivência da grande maioria depende de recursos provenientes dos cofres públicos brasileiros (especificamente do Plano Nacional de Assistência Estudantil); ocupam vagas nos cursos de graduação que poderiam ser de brasileiros; estabelecem residência na cidade por pelo menos quatro anos e por isso mesmo requerem infraestrutura em termos de moradia, alimentação, transporte, segurança pública, lazer e saúde; são portadores de matrizes culturais e étnicas muito distintas. Diante do exposto, cabe questionar: como conciliar os interesses da cidade com a missáo da universidade? Em que termos é possível descrever o que a cidade espera da UNILA, e o que a instituição tem feito para se aproximar da cidade, para se integrar ao ambiente urbano, para ser aceita e respeitada pelos habitantes da cidade? Em que medida o projeto original da UNILA tem sofrido alteraçóes decorrentes das pressôes exercidas pela população de Foz do Iguaçu?

No âmbito micro, a concretização da missão atribuída à UNILA em grande parte depende da compreensão do seu projeto de criaçấo e da capacidade de estudantes, professores, lideranças acadêmicas e técnico-educacionais ultrapassarem as limitações dos projetos individuais de cada um na direção de um projeto coletivo maior: a consolidação de uma universidade que se propóe a colaborar para o fortalecimento de uma regiáo historicamente enfraquecida por projetos exógenos aos interesses da população, em um momento marcado pelas exigências da 
globalização econômica. Por conseguinte, caberia questionar o nível de entendimento que esses atores têm do projeto que originou a criação da UNILA. Até que ponto eles acreditam nesse projeto e se dispóem a colaborar para a sua consolidação? Em que medida o encontro de culturas decorrente da realização do projeto de criação da universidade tem conseguido promover uma educação intercultural na direção da formação de uma identidade latino-americana? Concluída a formação superior, a instituiçáo e os egressos têm conseguido formular projetos cujo êxito depende da identidade e da consciência integracionista?

As incertezas referentes à implantação do projeto fundador da UNILA têm caráter externo e interno. $\mathrm{O}$ externo está atrelado à jurisdição e ao financiamento da universidade pelo governo federal brasileiro. No momento de sua criação, as condiçóes políticas e a conjuntura econômica permitiram a concretização e o financiamento do projeto unilateralmente, contudo o objetivo do governo brasileiro na época foi determinante para a criação dessa instituição. Da mesma forma, sua perpetuação se sujeitará aos objetivos políticos e à situação econômica do Brasil (no presente e no futuro), o que suscita incertezas quanto à preservação do projeto original de criação da instituição (CORAZZA, 2010; MARTINS, 2011). Já é perceptível que o contexto político e econômico recente do Brasil (2015-2019) é diferente do contexto de criação da UNILA (2003-2010). O governo federal tem alterado a política externa do país, imprimindo um caráter predominantemente conservador. Exemplo disso foi a recente desativação da UNASUL. Ademais, a economia do país está em recessão, marcada pelo alto índice de desemprego e pelo corte de gastos públicos, o que afeta diretamente o financiamento das universidades públicas (ROSSI; MELLO, 2017).

Não é sem razão que em julho de 2017 a sobrevivência da UNILA foi ameaçada, expondo a fragilidade da ideia de autonomia universitária. A tramitação da Medida Provisória no 785/2017 objetivava alterar não apenas a missão da universidade, mas modificar a sua nomenclatura. A proposta foi retirada de pauta pelo autor da medida após forte mobilização da comunidade interna da UNILA, que contou com apoio externo de mais de 130 entidades da sociedade civil organizada e de instituiçóes públicas e privadas, nacionais e internacionais (BRASIL, 2017).

$\mathrm{O}$ aspecto interno, por sua vez, refere-se ao interesse e à capacidade dos atores internos (estudantes, professores, técnicos educacionais e gestores acadêmicos) de concretizar a missão justificadora da criação da UNILA, nos limites do que foi previsto em seu projeto político, pedagógico e administrativo (MENEGHEL; AMARAL, 2016; RICOBOM, 2010; ROSEVICS, 2015). A divergência sobre os rumos da UNILA é fonte de desentendimento mesmo no âmbito interno. Enquanto um grupo trabalha obstinadamente para a consolidação de uma instituição fiel ao seu projeto fundador, outro trabalha para que a instituição assuma 
características de uma universidade hegemônica, bem classificada nos rankings internacionais (PROLO, 2019).

Assim sendo, não seria exagero afirmar que, embora o projeto de criação da UNILA se preste a colaborar para um ideal que motiva diversas geraçóes de acadêmicos, se mantém imaturo no campo das ações de sua implementação.

\section{Considerações finais}

A criação de uma universidade pública brasileira voltada para a integração regional teve origem em discussóes nos contextos sul e latino-americano. Inicialmente, as conjunturas política, econômica e social do Brasil favoreceram a sua criaçáo. Assim, a UNILA foi idealizada como um projeto capaz de aproximar acadêmicos de diferentes nacionalidades, culturas e visóes de mundo para que, juntos, conseguissem ultrapassar os antagonismos que impedem a integração social e cultural e criar condiçóes que permitissem a promoção de uma identidade latino-americana, semelhantemente à concepção de comunidade europeia, no Espaço Europeu de Ensino Superior.

Contudo, até o momento, a UNILA não conta com o apoio político de países da América Latina, como ocorre no Espaço Europeu de Ensino Superior. Apesar de ter sido criada em um contexto latino-americano em que se cogitava uma universidade supranacional, a instituição tem contado exclusivamente com iniciativas do governo brasileiro. A iniciativa isolada do Brasil, ao mesmo tempo em que referenda e viabiliza a criação de uma universidade de caráter internacional latino-americano, pode ser um elemento limitador para a concretização de seu projeto original. Tal fato tanto pode decorrer das restrições orçamentárias do governo federal brasileiro quanto de interesses políticos estranhos (contrários) ao projeto da instituição.

Em sua essência, a UNILA preocupa-se com o bem-estar coletivo e com o respeito à diversidade cultural, bem como com a qualidade da educaçáo, da produção e da difusão de uma ciência interessada - valores derivados dos ideais do Movimento de Córdoba e reforçados pela concepçáo de universidade de Darcy Ribeiro. Em seu cotidiano, tem batalhado para cultivar o caráter democrático das instituiçôes que funcionam "como instrumentos de mobilização e participação dos sujeitos no seu próprio processo emancipatório e de formação profissional, política, cultural e acadêmica" (SANTOS; ALMEIDA FILHO, 2008, p. 225). A instituição é uma síntese entre a "universidade necessária" (RIBEIRO, 1978) e "socialmente relevante" (MELLO; ALMEIDA FILHO; RIBEIRO, 2009), na medida em que faz diferença na transformação de uma sociedade carente de justiça social. 
O propósito integracionista que imprime sentido e razão para a UNILA é importante fonte de contribuição teórica para as pesquisas que objetivam discutir temas relacionados à internacionalização da educação superior, particularmente no âmbito da América Latina (PERROTTA, 2018). Apesar das tensões e incertezas retratadas neste ensaio, a existência da UNILA materializa as possibilidades de se investir em projetos de internacionalização inclusivos, generosos e solidários.

\section{Notas}

1. Atualmente, o Mercosul é composto de membros plenos e associados. Os membros plenos são: Argentina, Brasil, Paraguai, Uruguai e Venezuela (suspensa), e os membros associados são: Bolívia, Colômbia, Chile, Equador e Peru.

2. No período de 2003 a 2010 , a política externa brasileira projetou uma imagem soberana e altiva para ganhar visibilidade no cenário internacional, tendo como estratégia o direcionamento baseado em relaçôes de cooperação mais igualitárias e solidárias entre os chamados países do sul.

3. Entre os programas derivados da referida política estão: o Programa de Apoio a Planos de Reestruturação e Expansão das Universidades Federais (REUNI), o Programa Universidade para Todos (ProUni), a Universidade Aberta do Brasil (UAB) e o Plano Nacional de Assistência Estudantil (PNAES) (MENEGHEL; AMARAL, 2016). O REUNI, instituído pelo Decreto no 6.096, de 24 de abril de 2007, promove a reestruturação e expansão das universidades federais e a criação e interiorização de novas universidades.

\section{Referências}

ABBA, M. J. Límites y potencialidades para el desarrollo de una internacionalización de la educación superior necesaria: estudio de caso de La UNILA (Brasil) y La ELAM (Cuba). 278f. Tese (Doutorado em Educação) - Programa de Pós-Graduação em Educação, Universidade do Vale do Rio dos Sinos, São Leopoldo, 2018.

ARAÚJO, D. Nos caminhos da integração e da interculturalidade: os desafios da UNILA. Sures, n. 3, p. 1-17, 2014.

ARAÚJO, L. R. Associação Latino-Americana de Integração (ALADI). In: MERCADANTE, A. D. A.; CELLI-JUNIOR, U.; ARAÚJO, L. R. de (orgs.). Blocos econômicos e integraçáo na América Latina, África e Ásia. Curitiba: Juruá, 2008. p. 113-136.

AVEIRO, T. M. M. O programa Ciência sem Fronteiras como ferramenta de acesso à mobilidade internacional. Tear: Revista de Educaçáo, Ciência e Tecnologia, v. 3, n. 2, p. 1-21, 2014.

BRASIL. Instituto Nacional de Estudos e Pesquisas Educacionais Anísio Teixeira (INEP). Ministério da Educação (MEC). Microdados. Censo da Educação Superior: dados referentes 2010 
a 2017. Brasil: Instituto Nacional de Estudos e Pesquisas Educacionais Anísio Teixeira, 2018. Disponível em: <http://portal.inep.gov.br/web/guest/microdados>. Acesso em: 25 nov. 2018.

BRASIL. Universidade Federal da Integração Latino-Americana (UNILA). Plano de Desenvolvimento Institucional - PDI: 2013-2017. Brasil: UNILA, 2013. Disponível em: <www.unila.edu.br/sites/default/files/files/PDI\%20UNILA\%202013-2017.pdf>. Acesso em: 22 jan. 2019.

BRASIL. Universidade Federal da Integração Latino-Americana (UNILA). \#UNILAresiste. Brasil: UNILA, 2017. Disponível em: <https://www.unila.edu.br/noticias/unilaresiste-4 $>$. Acesso em: 4 mar. 2019.

CASTRO, A. A.; CABRAL NETO, A. O ensino superior: a mobilidade estudantil como estratégia de internacionalização na América Latina. Revista Lusófona de Educação, v. 21, n. 21, p. 69-96, 2012.

CERVO, A. L.; BUENO, C. História da política exterior do Brasil. 5. ed. Brasília: Ed. $\mathrm{UnB}, 2015$.

CHIBIAQUI, E. D. P.; LIMA, M. C.; NIHEI, O. K. Estudantes da UNILA e o processo de adaptação em Foz do Iguaçu. In: LIMA, M. C.; RICOBOM, G.; PROLO, I. (orgs.). A Universidade Federal da Integraçáo Latino-Americana na perspectiva da Academia. 2019. p. 217-247. (no prelo.)

CORAZZA, G. A UNILA e a integração latino-americana. Boletim de Economia e Política Internacional, v. 3, p. 79-88, 2010.

DIAS, M. A. R. CRES 2018: ¿Una nueva reforma de Córdoba? Prioridad a la esperanza y a la utopía contra la opresión y el oscurantismo. In: SUASNÁBAR, C.;VALLE, D. D.; DIDRIKSSON, A.; KORSUNSKY, L. (orgs.). Balance y desafíos hacia la CRES 2018: aportes para pensar la universidad latinoamericana. Buenos Aires: CLACSO, 2018. p. 29-48.

IMEA. UNILA Consulta Internacional: contribuições à concepção, organização e proposta político-pedagógica da UNILA. Foz do Iguaçu: IMEA, 2009a.

IMEA. UNILA em construçáo: um projeto universitário para a América Latina. Foz do Iguaçu: IMEA, 2009b.

LIMA, M. C.; SILVA, C. C. S.; PROLO, I.; TORINI, D. M. As contribuiçôes da consulta pública para o projeto de criação da Unila. Interfaces Brasil/Canadá, v. 16, n. 1, p. 210 232, 2016. http://dx.doi.org/10.15210/interfaces.v16i1.7682

MARTINS, D. V. A história da educaçáo superior na América Latina e o desafio integracionista da Unila. 106f. Dissertação (Mestrado em Educação) - Programa de PósGraduação em Educaçáo, Universidade Estadual do Oeste do Paraná, Cascavel, 2011.

MELLO, A. F. D. Globalizaçáo, sociedade do conhecimento e educaçáo superior: os sinais de Bolonha e os desafios do Brasil e da América Latina. Brasília: Editora UnB, 2011.

MELLO, A. F. D.; ALMEIDA FILHO, N. D.; RIBEIRO, R. J. Por uma universidade socialmente relevante. Atos de Pesquisa em Educaçáo, v. 4, n. 3, p. 292-302, 2009. http://dx.doi.org/10.7867/1809-0354.2009v4n3p292-302 
MENEGHEL, S.; AMARAL, J. Universidades internacionais na contracorrente. As propostas da Unila e da Unilab. Universidades, n. 67, p. 25-40, 2016.

MENEGHETTI, F. K. O que é um ensaio-teórico? Revista de Administraçáo Contemporânea, v. 15, n. 2, p. 320-332, 2011. http://dx.doi.org/10.1590/S1415$\underline{65552011000200010}$

MOROSINI, M. C.; DALLA CORTE, M. G.; GUILHERME, A. Internationalization of Higher Education: A Perspective from the Great South. Creative Education, v. 8, n. 1, p. 95-113, 2017. http://dx.doi.org/10.4236/ce.2017.81008

MUNOZ, A. M. E. Mutual intelligibility in the plurilingual context of the University of Latin-American integration: experiences, contact and plurilingual interaction. 271f. Tese (Doutorado em Ciências da Linguagem, Didática e Linguística) - Université Grenoble Alpes/Universidade Federal do Paraná, França, Brasil, 2016.

PECEQUILO, C. S.; CARMO, C. A. D. O Brasil e a América do Sul: relaçóes regionais e globais. Rio de Janeiro: Alta Books, 2015.

PERROTTA, D. La internacionalización de la universidad desde el MERCOSUR. In: DEL-VALLE, D.; SUASNÁBAR, C. (orgs.). Política y tendencias de la educación superior a diez ańos de la CRES 2008. Buenos Aires: IEC/CONADU/CLACSO, 2018. p. 219-235.

PROLO, I. Pertinência do projeto universitário latino-americano para a internacionalizaçáo da educaçáo superior: um estudo sobre a UNILA. 184f. Tese (Doutorado em Administração) - Programa de Pós-Graduação em Administração, Escola Superior de Propaganda e Marketing, São Paulo, 2019.

RIBEIRO, D. A universidade necessária. 3. ed. Rio de Janeiro: Paz e Terra, 1978.

RICOBOM, G. UNILA: a contribuição do ensino para a integração da América Latina. Revista do Centro de Educaçáo e Letras da Unioeste, v. 12, n. 1, p. 67-87, 2010.

RODRIGUES, D. O. O processo de uniformizaçáo normativa no âmbito do Mercosul e da União Européia: a marca comunitária. In: RICHTER, T.; SCHMIDT, R. (orgs.). Integraçáo e cidadania europeia. Sáo Paulo: Saraiva, 2011. p. 469-487.

ROSEVICS, L. O Mercosul educacional e a criação da UNILA no início do século XXI: por uma integraçáo regional via educação. 149f. Tese (Doutorado em Economia Política Internacional) - Programa de Pós-Graduação em Economia Política Internacional, Instituto de Economia, Universidade Federal do Rio de Janeiro, Rio de Janeiro, 2015.

ROSSI, P.; MELLO, G. Choque recessivo e a maior crise da história: A economia brasileira em marcha à ré. Nota do Cecon, n. 1, 2017.

RUBIÃO, A. História da Universidade: genealogia para um modelo participativo. Coimbra: Almedina, 2013.

SANTOS, B. D. S. Pela máo de Alice: o social e o político na pós-modernidade. 9. ed. Coimbra: Almedina, 2013. 
SANTOS, B. D. S.; ALMEIDA FILHO, N. D. A universidade no século XXI: para uma universidade nova. Coimbra: Almedina, 2008.

SCHAPOSNIK, E. C. As teorias da Integraçáo e o Mercosul: estratégias. Florianópolis: Ed. da UFSC, 1997.

SPELLER, P. Prefácio. In: LIMA, M. C.; CONTEL, F. B. (orgs.). Internacionalizaçáo da educação superior: naçóes ativas, nações passivas e a geopolítica do conhecimento. São Paulo: Alameda, 2011. p. 7-10.

TRINDADE, $\mathrm{H}$. Por um novo projeto universitário: da "universidade em ruínas" à "universidade emancipatória”. In: SOUSA JUNIOR, J. G. D. (orgs.). Da universidade necessária à universidade emancipatória. Brasília: Editora da UnB, 2012. p. 89-142.

\section{SOBRE OS AUTORES}

Ivor Prolo é Doutor em Administração pelo Programa de Pós-Graduação em Administração PPGA/ESPM e profissional na Universidade do Estado de Mato Grosso (UNEMAT).

Manolita Correia Lima é Doutora em Educação pela Universidade de São Paulo (USP); Professora titular e coordenadora do Núcleo de Inovaçáo Pedagógica da da Escola de Propaganda e Marketing (ESPM).

Gonçalo Canto Moniz é Doutor em Arquitectura pela Universidade de Coimbra (UC) e membro da Direcção Executiva do Centro de Estudos Sociais (CES) da UC.

Recebido em 18 de janeiro de 2018.

Aceito em 2 de abril de 2019. 